\title{
Análise de Séries Históricas de Dados de Temperatura e Precipitação no Litoral Brasileiro
}

\author{
Tiago Nicolay Rodrigues ${ }^{(a)}$, Eduardo Manuel Rosa Bulhões ${ }^{(b)}$ \\ (a) Bacharelando em Geografia. Laboratório de Geografia Física. Instituto de Ciências da Sociedade e \\ Desenvolvimento Regional. Universidade Federal Fluminense, tiagonicolay@ gmail.com \\ (b) Prof. Adjunto. Laboratório de Geografia Física. Programa de Pós-Graduação em Geografia. Instituto de \\ Ciências da Sociedade e Desenvolvimento Regional. Universidade Federal Fluminense \\ eduardobulhoes@id.uff.br
}

Eixo: Climatologia em diferentes níveis escalares: Mudanças e variabilidades

\begin{abstract}
Resumo
O território brasileiro, marcado por sua grande extensão, possui diferenciados regimes de temperatura e precipitação, variando o clima de Norte a Sul, em resposta à complexidade da atmosfera e atuação de diversos fatores que influenciam o clima. Obtiveram-se dados meteorológicos de estações localizadas na zona costeira do Brasil e posteriormente a aplicação de procedimentos estatísticos para geração dos resultados. Observou-se uma homogeneidade da temperatura na zona costeira da Região Norte, o que não acontece em relação à pluviosidade, caracterizando-a como o maior total pluviométrico. A zona costeira do Nordeste também apresenta pouca variabilidade na temperatura na área estudada, embora com valores menores de precipitação. Na zona costeira da Região Sul, tem-se a distribuição homogênea da precipitação e a marcante variação da temperatura média e na zona costeira do Sudeste, o máximo pluviométrico foi registrado em janeiro e fevereiro e o mínimo em julho e agosto.
\end{abstract}

Palavras chave: climatologia, zona costeira, séries históricas.

\section{INTRODUÇÃO}

O território brasileiro é marcado por uma relevante característica, a qual denomina-se tropicalidade, que é o predomínio de um clima com altas temperaturas e altos índices pluviométricos que ocorrem especialmente no verão. Adicionalmente a atuação de outros fatores climáticos influencia de maneira significativa as variações locais e regionais desencadeando diferenças de um lugar para o outro. (TORRES e MACHADO, 2011)

Conforme Calvalcanti et al. (2009), a atmosfera caracteriza-se por sua complexidade, de forma que o tempo que é sentido no dia a dia, a ocorrência de chuvas, calor, frio estão relacionados à passagem de frentes frias e quentes, ciclones e anticiclones, ondas atmosféricas, tempestades, entre outros, que exercem influência na zona costeira.

Numa definição mais comumente utilizada, a Zona Costeira caracteriza-se como "o espaço geográfico de interação do ar, do mar e da terra, incluindo seus recursos ambientais" (BRASIL, 1997). Ou como bem definem Rodriguez e Windevoxhel (1998) “o espaço delimitado pela interface entre o oceano e a 
terra, ou seja, a faixa terrestre que recebe influência marítima e a faixa marítima que recebe influência terrestre".

Como coloca Marin et al. (2000), é bastante evidente que as variações dos elementos meteorológicos no decorrer do ano determinam as características climáticas de uma região, de maneira que estrutura sócia econômica e até mesmo seus meios de produção são dependente dessas características.

De acordo com Baba et al. (2014), a análise de dados climáticos fornece suporte para a previsão de fenômenos, para a avaliação de dados históricos e para a tomada de decisões em diferentes campos de estudo, como por exemplo na agricultura e na saúde. Neste caso, os dados podem dar suporte para o exercício de diferentes estratégias de gestão ambiental na zona costeira brasileira. Hoje, o desenvolvimento e a coleta dos dados são feitos por estações meteorológicas de diferentes ordens na superfície terrestre, que coletam as informações meteorológicas (temperatura, umidade, pressão atmosférica, precipitação, direção e velocidade dos ventos, radiação solar) representativas da área em que está localizada (INMET, 2011).

O objetivo geral do presente trabalho é uma caracterização climática da zona costeira brasileira e especificamente a análise inicial da zona costeira do país através das variáveis temperatura e precipitação.

\section{CARACTERIZAÇÃO DA ÁREA DE ESTUDO}

A Zona Costeira se estende da foz do rio Oiapoque $\left(04^{\circ} 52^{\prime} 45^{\prime}\right.$ 'N) à foz do rio Chú $\left(33^{\circ} 45^{\prime} 10^{\prime \prime} \mathrm{S}\right)$ e dos limites dos municípios da faixa costeira, a oeste. A faixa terrestre, de largura variável, se estende por aproximadamente 10.800 quilômetros ao longo da costa, se contabilizadas suas reentrâncias naturais, e possui uma área de aproximadamente $514 \mathrm{mil} \mathrm{km}^{2}$, dos quais $324 \mathrm{mil} \mathrm{km²}$ correspondem ao território de 395 municípios distribuídos ao longo dos 17 estados litorâneos, concentrando 13 das 27 capitais brasileiras, algumas das quais, regiões metropolitanas onde vivem milhões de pessoas, um indicador do alto nível de pressão antrópica a que seus recursos naturais estão submetidos (MMA, 2010).

\section{MATERIAIS E MÉTODOS}

Para Mendonça e Dani-Oliveira (2007), a análise dos dados deve estar baseada em longas séries estatísticas de dados meteorológicos de diferentes localidades para que o resultado obtido tenha representatividade climática na região.

Os elementos do clima obedecem a um padrão, expresso por um total anual e variações mês a mês. É o que se designa de normal, obtida pelas medias de trinta anos de registros. As mais recentes, segundo a Organização Meteorológica Mundial correspondem ao período de 1961-90, aplicáveis a todo o globo a fim de que se possa estabelecer uma comparação. (CONTI, 1998). 
Foram obtidos os dados de trinta estações (Figura I) localizadas em municípios da Zona Costeira do Brasil, definidos de acordo com o Plano Nacional de Gerenciamento Costeiro, junto ao Banco de Dados Meteorológicos para Ensino e Pesquisa - (BDMEP), que abriga dados meteorológicos diários e mensais em forma digital. Esse conjunto forma uma série histórica das várias estações meteorológicas convencionais da rede de estações do Instituto Nacional de Meteorologia - INMET com milhões de informações, referentes às medições diárias, de acordo com as normas técnicas internacionais da Organização Meteorológica Mundial (INMET, 2011)

A partir dos dados meteorológicos disponibilizados pelo banco de dados do BDMEP, por meio de arquivos texto e posteriormente convertidos em tabelas, foram obtidos dados de precipitação (total mensal) e temperatura (máxima média, mínima média e compensada). A análise inicial foi feita utilizando os programas Statistica 7 e MsExcell 2007.

\section{RESULTADOS PARCIAIS}

A figura 1, a seguir, representa a distribuição das estações meteorológicas na Zona Costeira junto aos climogramas dos litorais das Regiões Norte e Nordeste, numa análise feita com as médias mensais de precipitação e temperatura entre 1961 até 2015 . A série em vermelho indica a temperatura e a série em azul, a precipitação. Para o litoral da Região Norte, observa-se que os maiores valores de precipitação $(511 \mathrm{~mm}$ e $455 \mathrm{~mm}$ ) ocorreram respectivamente nos meses de março e abril, e a temperatura média indicou pouca variação, com valores entre $25,9^{\circ} \mathrm{C}$ em fevereiro a $27,8^{\circ} \mathrm{C}$, em outubro, mês em que foi registrada e menor média de acúmulo mensal de precipitação para a região, com $56 \mathrm{~mm}$. 


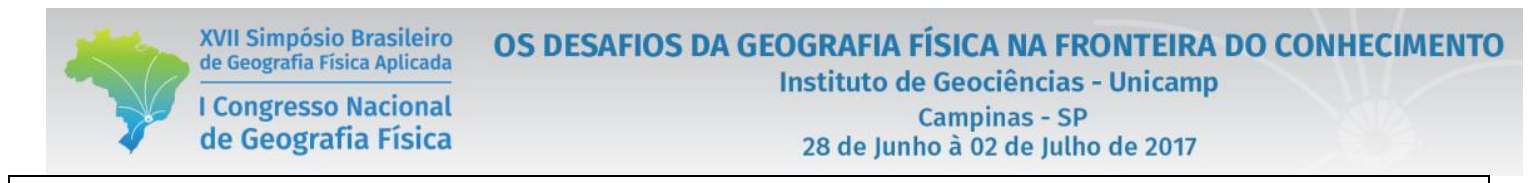

Distribuição das estações meteorológicas e climogramas das Regiões Norte e Nordeste do Litoral Brasileiro
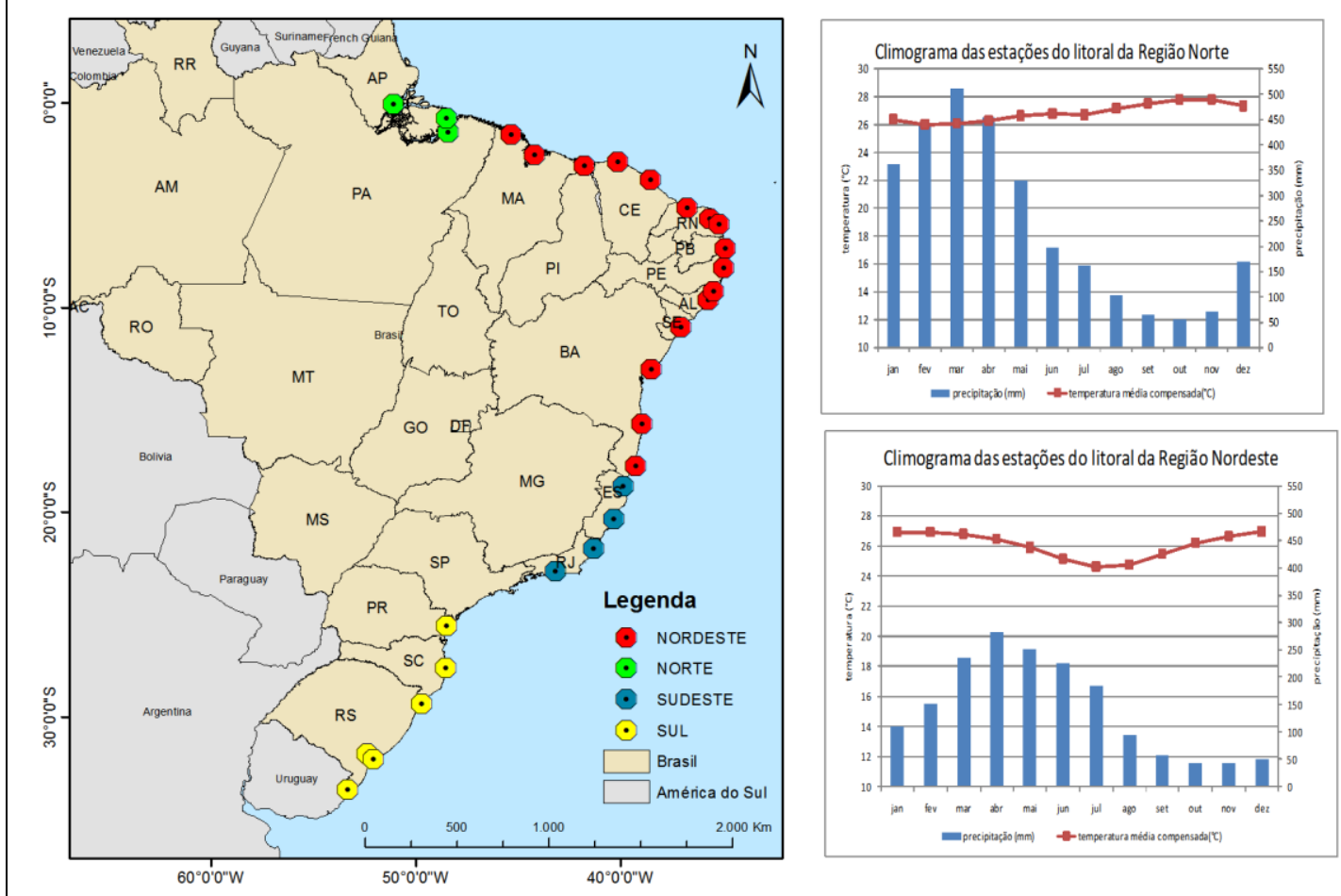

Figura 1 - Distribuição das estações meteorológicas e climogramas das Regiões Norte e Nordeste

Na Região Nordeste, também é possível observar pouca variação da temperatura média, com valores de $26,9^{\circ} \mathrm{C}$ para os meses de dezembro, janeiro e fevereiro e $24,6^{\circ} \mathrm{C}$ no mês de julho. Quanto à precipitação, os valores são bastante inferiores em comparação com a Região Norte, registrando no meses de abril e maio, $283 \mathrm{~mm}$ e $252 \mathrm{~mm}$, respectivamente. Os menores índices de precipitação foram registrados nos meses de outubro e novembro, com $43 \mathrm{e} 44 \mathrm{~mm}$, respectivamente.

A figura 2, a seguir representa a distribuição das estações meteorológicas na Zona Costeira junto aos climogramas dos litorais das Regiões Sudeste e Sul. Na Região Sudeste, a variação da temperatura média mostra-se pouco mais relevante que nas regiões anteriores, com valores médios de $27^{\circ} \mathrm{C}$ em fevereiro e $21,6^{\circ} \mathrm{C}$ em julho, variando $5,4^{\circ} \mathrm{C}$, que caracteriza uma variação maior do que a soma das variações das regiões observadas anteriormente, com $4,2^{\circ}$ C. Quanto a precipitação, os maiores valores foram registrados nos meses de novembro e dezembro, com valores de $166 \mathrm{~mm}$ e $152 \mathrm{~mm}$, respectivamente. $\mathrm{O}$ mês de agosto registrou o menor valor de precipitação para todos os meses e regiões em análise, com 41 mm, valor abaixo da média para a Região Sudeste, com 94 mm. 

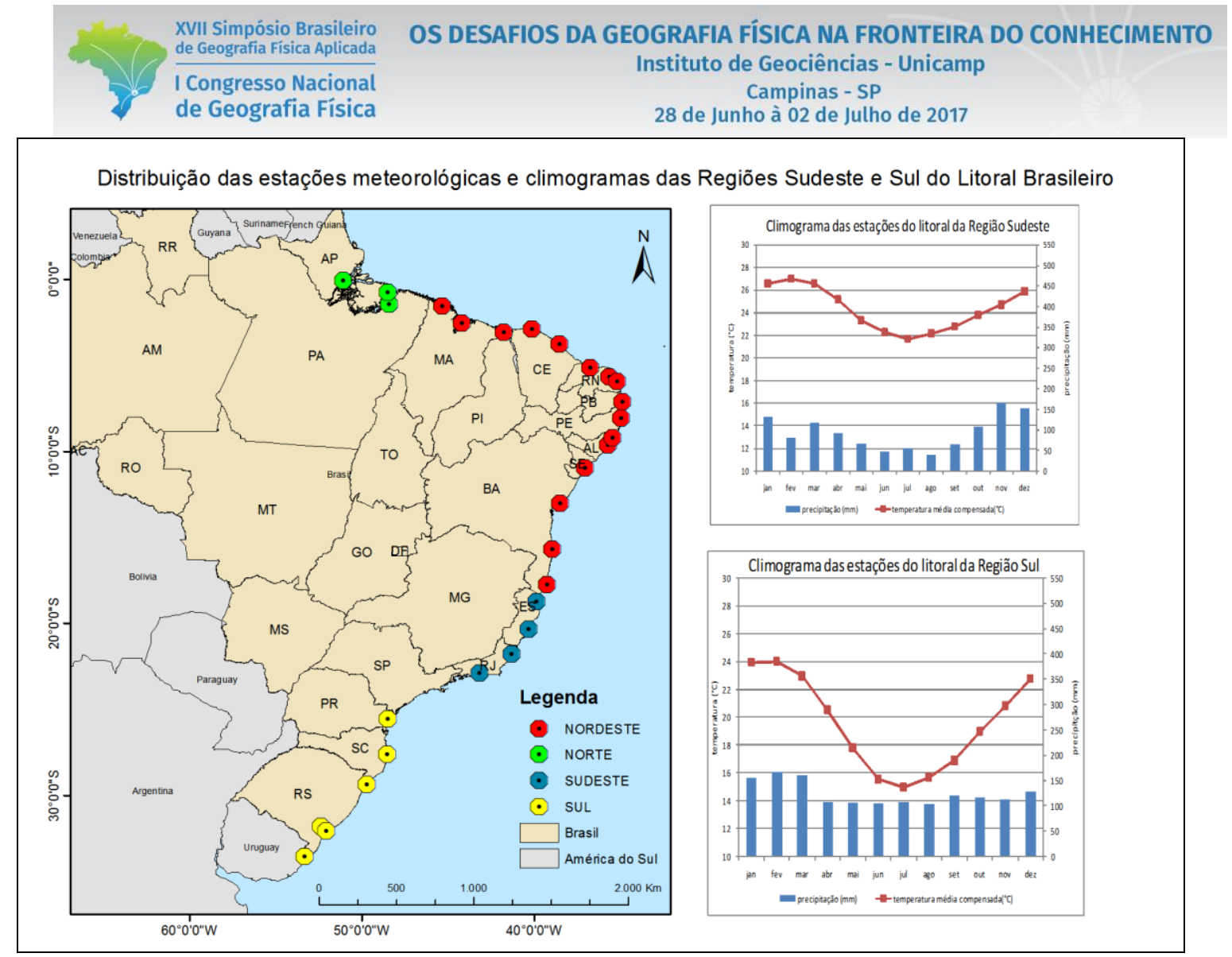

Figura 2 - Distribuição das estações meteorológicas e climogramas das Regiões Sudeste e Sul do Litoral Brasileiro

Na Região Sudeste, a variação da temperatura média mostra-se pouco mais relevante que nas regiões anteriores, com valores médios de $27^{\circ} \mathrm{C}$ em fevereiro e $21,6^{\circ} \mathrm{C}$ em julho, variando $5,4^{\circ} \mathrm{C}$, que caracteriza uma variação maior do que a soma das variações das regiões observadas anteriormente, com $4,2^{\circ}$ C. Quanto a precipitação, os maiores valores foram registrados nos meses de novembro e dezembro, com valores de $166 \mathrm{~mm}$ e $152 \mathrm{~mm}$, respectivamente. O mês de agosto registrou o menor valor de precipitação para todos os meses e regiões em análise, com $41 \mathrm{~mm}$, valor abaixo da média para a Região Sudeste, com 94 mm.

A Região Sul caracteriza-se pela alta variação da temperatura média ao longo do ano, registrando uma variação de $9^{\circ} \mathrm{C}$ entre fevereiro e julho, com valores de $24^{\circ} \mathrm{C}$ e $15^{\circ} \mathrm{C}$, respectivamente. Quanto a precipitação, a distribuição anual sobre esta Região se dá de forma bastante uniforme visto que os maiores e os menores valores são relativamente próximos, com $167 \mathrm{~mm}$ em fevereiro e $104 \mathrm{~mm}$ em agosto, respectivamente.

\section{CONSIDERAÇÕES FINAIS}

$\mathrm{Na}$ análise inicial dos dados foram apresentados os valores máximos, médios e mínimos de temperatura e precipitação compilados na forma de climogramas que agregaram estações referentes aos municípios que compõe os macrocompartimentos do litoral brasileiro conforme Silveira (1964) apud Muehe (1998). Este recorte permitiu diferenciações significativas que possibilitarão um aprofundamento da interpretação dos elementos e fatores climáticos atuantes. Neste sentido, cabe 


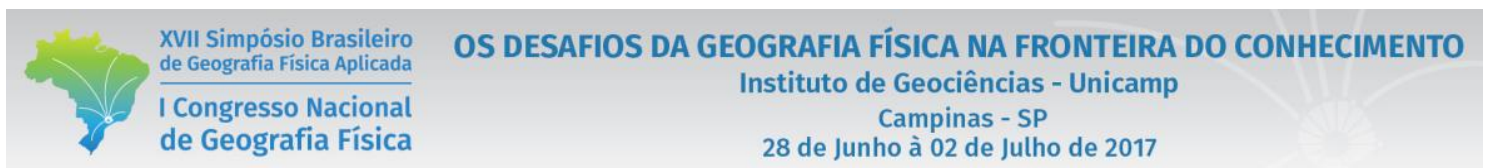

destacar as variações crescentes na amplitude térmica desde as mais baixas para as mais altas latitudes e a distribuição anual dos volumes médios de precipitação que passam de mal a bem distribuidas também considerando das mais baixas para as mais altas latitudes. Para a zona costeira brasileira em particular, elementos da interação oceano-atmosfera como temperatura da superficie do mar e salinidade podem ser melhor entendidos/explicados pelos dados de precipitação e temperatura, assim como elementos associados ao aporte e transporte de sedimentos em áreas de maior precipitação e a ocorrência de feições costeiras como dunas nas áreas mais secas.

\section{REFERÊNCIAS BIBLIOGRÁFICAS}

BABA, R. K; VAZ, M. S. M. G; COSTA, J; Correção dedados agrometeorológicos utilizando métodos estatísticos. UFPG, Ponta Grossa, PR. Revista Brasileira de Meteorologia. v.29, n.4, 515 - 526, 2014.

BRASIL. Constituição de 1988. Lei ${ }^{\circ}$ 7.661, de 16 de maio de 1988. Plano Nacional de Gerenciamento Costeiro (PNGC II). 1997.

CAVAlCANTI, I. F. A; FERREIRA, N. J; SILVA, M. G. A. J; DIAS, M. A. F. S; Tempo e clima no Brasil. São Paulo: Oficina de textos, 2009. 464p

CONTI, J. B. Clima e Meio Ambiente. 5. ed. São Paulo: Atual, 1998. 96p.

INMET. Instituto Nacional de Meteorologia. Nota técnica nº 001/2011/SEGER/LAIME/CSC/INMET. Rede de Estações Meteorológicas Automáticas do INMET. 2011.

MARIN, F. R.; SENTELHAS, P. C.; NOVA, A. V. Influência dos fenômenos EI Niño e La Niña no clima de Piracicaba, SP. In: Revista Brasileira de Meteorologia. v. 15, n. 1, 123-129, 2000.

MENDONÇA, F.; DANNI-OLIVEIRA, I. M. Climatologia: noções básicas e climas do Brasil. São Paulo: Oficina de Texto, 2007. 206 p.

MMA. Gerência de Biodiversidade Aquática e Recursos Pesqueiros. Panorama da conservação dos ecossistemas costeiros e marinhos no Brasil. Brasília: MMA/SBF/GBA, 2010. 148 p.

MUEHE, D. O Litoral Brasileiro e sua Compartimentação. In: Guerra, A. J. T. \& Cunha, S.B. (org). Geomorfologia do Brasil. Cap. 7. Ed. Bertrand Brasil, 1998

RODRIGUEZ, J. J. e WINDEVOXHEL, N. J. Análisis Regional de La situación de La zona marina costera Centroamericana. BID, Washington D. C. No - ENV 121, 1998

TORRES, F. T. P; MACHADO, P. J. O. Introdução à climatologia. São Paulo: Cengage Learning, 2011. 250p 